\title{
Efectos y sentidos de la palabra de los represores.
}

\section{Reseña de: Feld, Claudia y Salvi, Valentina (Eds.) (2019). Las voces de la represión. Declaraciones de perpetradores de la dictadura argentina. Buenos Aires: Miño y Dávila.}

\author{
Ana Laura Sucari \\ anasucari@hotmail.com \\ Universidad de Buenos Aires - CONICET, Argentina
}

Cita sugerida: Sucari, A. L. (2021). Efectos y sentidos de la palabra de los represores [Revisión del libro Las voces de la represión. Declaraciones de perpetradores de la dictadura argentina por Claudia Feld y Valentina Salvi (Eds.)]. Sociohistórica, 47, e137. https://doi.org/10.24215/18521606e137

Las voces de la represión. Declaraciones de perpetradores de la dictadura argentina presenta un gran aporte para repensar los sentidos y efectos de los discursos de los represores de la última dictadura (1976-1983). Se trata de una compilación editada por Claudia Feld y Valentina Salvi que indaga en las declaraciones públicas de los represores comprendidas como procesos sociales, políticos y memoriales.

La obra plantea la existencia de una relación dinámica entre las declaraciones públicas de los perpetradores y la coyuntura histórico-política en la que éstas se produjeron. De este modo, los autores y las autoras demuestran que las declaraciones no se dieron de forma aislada, sino que necesitaron de determinadas condiciones de posibilidad para desarrollarse. En este sentido, se advierten cuatro "oleadas" en las que se desplegaron las voces de los perpetradores: la primera en los años 1984 y 1985, asociada al show del horror y a la pugna por los sentidos sobre el pasado; la segunda, a mediados de los años noventa, por medio de las intervenciones mediáticas de los represores; luego, las declaraciones que se dieron en el marco de los Juicios por la Verdad; por último, una cuarta oleada ligada a los discursos de los represores en los juicios por crímenes de lesa humanidad a partir del 2005. De este modo, se resalta la importancia social de los dichos de los perpetradores en tanto despliegues performativos. Asimismo, resulta interesante que el trabajo analiza el discurso de represores de diferentes rangos militares y policiales que se desempeñaron en diversas regiones del país.

El estudio de las declaraciones de los represores, lejos de repetir acríticamente sus discursos o restar especificidad a los crímenes cometidos, aborda con inteligencia y sensibilidad los sentidos de sus palabras, complejizando la creencia de que entre los integrantes de las Fuerzas Armadas y de seguridad ha reinado un "pacto de silencio". Contrariamente al sentido común que sostiene que los perpetradores "no hablaron", se 
demuestra que no sólo lo hicieron, sino también que con sus intervenciones relativizaron, negaron, falsearon, confesaron, ocultaron y, en algunos casos, aportaron información. Asimismo, la obra analiza las expectativas sociales que rondan en torno a su palabra, ya que existe una cierta expectativa de que en cada declaración revelarán algún secreto que sólo ellos conocen sobre el accionar represivo. Por último, da cuenta del modo en que los actos de habla de los represores tienen la capacidad de prolongar o terminar sus crímenes, dado que sus dichos surten efectos en los momentos en los que son producidos.

El libro comienza con una introducción de Feld y Salvi, en la cual delinean la perspectiva y el marco conceptual que comparten el conjunto de los trabajos. Luego, se estructura en diez artículos independientes agrupados en cuatro momentos diferenciados, a partir del período en que fueron emitidas las declaraciones del represor que estudian: las voces del régimen, de la transición, de la impunidad y, finalmente, las voces de los estrados.

La primera parte del libro, titulada las "Voces del régimen: justificar, silenciar, encubrir", está compuesta por artículos que ponen el foco en los altos mandos de las Fuerzas Armadas, que utilizaron su rango y su conocimiento para dirigirse a sus subordinados, a la sociedad en general y a "la Historia". En este sentido, las diversas autoras trabajan sobre los discursos oficiales del régimen y cómo estos se articulaban con las cuestiones que debían ser ocultadas. A modo de apertura, Eva Muzzopappa se centra en el caso del contraalmirante Horacio Mayorga, autoridad militar a cargo de la base Almirante Zar durante la Masacre de Trelew. En sus declaraciones públicas, Mayorga buscó erigirse como un caballero, resaltando la disciplina y obediencia reinante en el interior de la Armada, con el fin de reforzar la moral de los marinos y evitar su desprestigio. El diario bahiense La Nueva Provincia contribuyó a reforzar esa imagen con sucesivas publicaciones sobre el contraalmirante. Con el regreso a la democracia, el gentleman adoptó una postura irreverente al repudiar la falta de virilidad de la clandestinidad, más que las prácticas clandestinas en sí mismas. Como demuestra la autora, Mayorga, con sus dichos, buscaba relegitimar los valores caballerescos puestos en duda por los crímenes cometidos por la Armada durante la dictadura. En 2006, el contralmirante fue imputado en el marco de la causa judicial por la Masacre de Trelew. Si bien volvió a intentar resaltar su figura caballeresca, en aquella coyuntura su palabra no surtió los mismos efectos que había tenido en los períodos anteriores gracias al avance de los organismos de derechos humanos.

En el segundo artículo, Paula Canelo se ocupa de analizar la "posición imposible" en la que se encontraba el Ministro del Interior Albano Harguindeguy. Encargado de la articulación entre las esferas legales del régimen y sus acciones clandestinas, el "superministro" se pronunció periódicamente, teniendo que oscilar entre las cuestiones legales y cotidianas que podía decir y las relativas al sistema represivo ilegal que debía silenciar. Ya en democracia, Harguindeguy buscó transformarse en un hombre común, deslindándose de aquello que conocía y de lo que era responsable. No obstante, como consecuencia de la posición imposible que había ocupado durante tantos años, sus dichos en el Juicio a las Juntas evidenciaron su participación en el accionar represivo. El puntilloso estudio da cuenta del modo en que el período de impunidad habilitó a Harguindeguy a recrudecer su cinismo y a continuar expresándose sin aportar información, con un fuerte sarcasmo en sus palabras y una postura heroica y reivindicativa de los hechos.

El trabajo de Valentina Salvi aborda los discursos públicos de Jorge Rafael Videla sobre los desaparecidos en diversos períodos históricos. Cuando era presidente del régimen, definió a los desaparecidos como una incógnita, como aquello que no era posible nombrar. En los momentos en los que debió referirse al tema, buscó instalar la idea de que las desapariciones habían sido excesos cometidos por los cargos medios en la "guerra contra la subversión". Luego, Salvi analiza tres entrevistas periodísticas en las cuales Videla habló del tema, en 1998/1999, 2011 y 2012. El excomandante en jefe utilizó las entrevistas para dirigirse a la sociedad argentina y deslegitimar los juicios y la palabra de los sobrevivientes. En ellas, sostuvo que las desapariciones habían sido una solución al propio devenir de "la guerra" y que su carácter clandestino había sido para ocultar los crímenes cometidos. En definitiva, Videla entendía que las Fuerzas Armadas habían logrado una victoria militar, pero sufrido una derrota política. 
"Voces de la transición: revelar, arengar" es la segunda parte del libro, que se encarga de analizar las declaraciones surgidas durante la transición democrática a la par del show del horror, la investigación y publicación del informe de la CONADEP y el Juicio a las Juntas. Claudia Feld analiza las entrevistas que realizó la revista La Semana a Raúl Vilariño. El semanario buscó componer la figura del represor del mismo modo que lo hacía con las celebridades, utilizando un tono sensacionalista, característico del show del horror, y combinando las declaraciones de Vilariño sobre la ESMA con fotografías y datos de su vida personal. En sus largos testimonios, el represor alternó entre la culpa y el cinismo, y brindó detalles macabros sobre lo sucedido en el interior de los CCD. Si bien esos detalles no aportaron nueva información, en esa coyuntura de pugna por los sentidos del pasado cumplió con las expectativas sociales acerca de lo que se esperaba de las declaraciones de los represores. De este modo, la autora propone que la revista buscó armar un modelo de perpetrador a través del cual, conociendo a Vilariño, fuera posible reconocer a todos los represores con funciones semejantes, pero desde una perspectiva que invisibilizaba el carácter estructural y sistemático de la represión.

Diego Galante, por su parte, propone indagar en las declaraciones de los excomandantes durante el Juicio a las Juntas buscando los puntos en común de aquellos testimonios y delineando algunas generalidades de las exposiciones, como la ansiedad por hablar. Asimismo, el autor da cuenta del modo en que la responsabilidad y la culpabilidad fueron representadas durante el Juicio como cuestiones escindidas, dado que en sus discursos los oficiales asumían la responsabilidad por las órdenes impartidas a sus subordinados, pero quedaban eximidos de la culpabilidad en el caso de que los rangos inferiores no se hubieran apegado a la obediencia y hubiesen tenido conductas desviadas. A través de esta construcción retórica, los excomandantes se hacían "responsables de todo en general, y de nada en particular", con lo que buscaban aminorar su condena penal y salvaguardar su honor militar frente a sus subordinados.

Las leyes de impunidad y los indultos frenaron la persecución penal a los represores y posibilitaron su aparición pública en los medios de comunicación. La tercera parte del libro, "Voces de la impunidad: jactarse, negar, eludir", explora las voces que, en este contexto, se caracterizaron por reivindicar la represión, desestimar la palabra de los sobrevivientes y negar los delitos de lesa humanidad. Luciana Messina aborda el caso de Julio Simón -cuyo apodo durante la dictadura era “Turco Julián”-. En 1995, Simón asistió a programas televisivos en los que reivindicó el accionar dictatorial y responsabilizó a "la subversión" por lo sucedido en los años setenta. Si bien la información brindada no resultó reveladora, al justificar el carácter clandestino de la represión el “Turco Julián” aceptó que había existido un plan de tortura y aniquilamiento del cual él había sido parte activa y central. Años más tarde, en su declaración judicial por una causa de apropiación y participación en el circuito $\mathrm{ABO}$, Simón decidió negar su participación en el aparato represivo. Se excusó en su posición de subordinado, la obediencia que debía a sus superiores, y redujo sus tareas a cuestiones administrativas. Como apunta Messina, Simón buscó acomodarse a los distintos períodos, utilizando la impunidad para reivindicar su accionar y desplazándose del centro de la escena al momento de enfrentar los estrados.

El siguiente artículo se centra en la voz de los represores en los programas televisivos y, en particular, en el caso del exjefe de la Policía de la provincia de Buenos Aires, Miguel Etchecolatz. Claudia Feld analiza la invitación de Mariano Grondona, en el programa "Hora Clave”, a Etchecolatz y a una de sus víctimas, Alfredo Bravo. Para la autora, Grondona pretendió generar un diálogo "entre iguales". Sin embargo, demuestra que los intentos por equiparar las voces de víctimas y victimarios reprodujeron la violencia pretérita reinante dentro de los CCD, empoderando al perpetrador y revictimizando a Bravo, que tuvo que defenderse de las acusaciones de quien lo había torturado. Asimismo, la presentación de las voces de sobrevivientes y represores de forma homogénea habilitó el surgimiento de relatos negacionistas como una simple postura sobre lo sucedido en el pasado. En definitiva, los artículos destinados a la impunidad dan cuenta de que en este período, a falta de mediaciones institucionales, se generaron condiciones de enunciación que posibilitaron a los represores poner en disputa los sentidos sobre el pasado, reivindicar la dictadura y negar la sistematicidad de la represión con sus testimonios. 
Iluminando otro aspecto del período de impunidad, Enrique Andriotti Romanin examina las declaraciones del teniente coronel Julián Corres en el Juicio por la Verdad de Bahía Blanca. En 1999, el oficial, que aún revistaba como activo, fue citado como testigo y prestó declaración testimonial. En este contexto, Corres reconoció haber operado en el CCD "La Escuelita” y brindó datos sobre su funcionamiento que coincidían con los relatos de los sobrevivientes. Durante el juicio, una sobreviviente lo acusó de haberla torturado y de haber abusado de ella. Por pedido de la querella, los jueces acusaron a Corres de falso testimonio y solicitaron un careo con su víctima. El autor analiza las estrategias discursivas utilizadas por Corres a lo largo del juicio: el haber sido citado inicialmente en calidad de testigo evidenciaba la impunidad de la que gozaba el represor, mientras que cuando se convirtió en imputado buscó mitigar su participación y optó por el silencio.

La cuarta parte del libro, "Voces de los estrados: purificarse, testimoniar", retoma las voces que se erigieron a partir de la inconstitucionalidad de las leyes de "Punto Final" y "Obediencia Debida" y la reapertura de los juicios. El artículo de Santiago Garaño examina el caso del tucumano Omar Eduardo Torres, testigo anómalo en tanto había sido gendarme en el Operativo Independencia, y que, desde el informe de la CONADEP, brindó su testimonio de forma continua. Por medio de este caso, el autor analiza el modo en que los organismos de derechos humanos otorgaron -o no- legitimidad a la palabra de los testigos en la esfera pública. Así, a diferencia de otro gendarme que inicialmente se encontraba en su misma posición, e incluso de una pareja de sobrevivientes considerados colaboradores, Torres logró obtener la categoría de "testigo" gracias a su acercamiento y cooperación con las abogadas de los organismos. En este sentido, el artículo habilita la posibilidad de repensar el modo en que las categorías de represor, víctima y testigo encarnan relaciones de poder y, por lo tanto, pueden modificarse a lo largo de la historia.

Por último, Valentina Salvi explora la cuestión de la verdad en la palabra de los represores. Para ello, indaga en los dichos de Eduardo "el Tucu" Constanzo, perpetrador rosarino, quien habló abiertamente durante la década del noventa y en el juicio Guerrieri I. Constanzo aportó información novedosa que permitió identificar a otros represores y localizar el sitio donde se habían inhumado compañeros, y brindó datos claves para la restitución de una nieta apropiada, con lo que rompía el pacto de silencio. No obstante, en su declaración se valió de un lenguaje cínico, desapegado de las víctimas, en la cual él quedaba por fuera del relato. La autora da cuenta del modo en que, si bien brindó información útil y novedosa, tanto la Fiscalía como los organismos de derechos humanos buscaron ratificar sus dichos con testimonios de sobrevivientes y pruebas materiales. De este modo, Salvi introduce la cuestión de la veracidad, pues señala la existencia de una expectativa social sobre que los represores tengan una "verdad más verdadera" que develar, pero cuyas declaraciones acarrean una gran sospecha por provenir de los mismos perpetradores.

En suma, Las voces de la represión. Declaraciones de perpetradores de la dictadura argentina presenta un profundo análisis sobre las voces de los represores que invita a la reflexión sobre los efectos de sus discursos a partir de la articulación con la coyuntura política en la que fueron enunciados. La obra resulta de gran valor, tanto académico como político, ya que contribuye a repensar el pasado reciente, los procesos de memoria y la elaboración del terror; al tiempo que reafirma la importancia de los juicios de lesa humanidad pues demuestra que la impunidad no llevó a los represores a decir la verdad por encontrarse exentos de persecución penal. De este modo, se aborda de forma rigurosa un aspecto tan controvertido como significativo de nuestra historia reciente. La obra deja pendiente un análisis con perspectiva de género, que incorpore el estudio de las voces de las represoras e indague en la configuración y representación de las masculinidades. Quien avance en esta dirección encontrará en este libro un punto de partida sólido e ineludible. Para concluir, al tiempo que los perpetradores continúan siendo juzgados, las autoras y los autores revisitan los efectos de la palabra pública de los represores y contribuyen a repensar su impacto en la sociedad argentina actual. 